\title{
Versiones decimonónicas de la leyenda de la Judía de Toledo
}

\author{
JUAN A. RÍOS CARRATALÁ \\ Universidad de Alicante
}

La leyenda de la Judía de Toledo y Alfonso VIII ha sido sin lugar a dudas una de las más fructíferas en el ámbito de la literatura nacional, e incluso internacional. Nombres tan destacados como Lope de Vega, Juan Bautista Diamante, Luis de Ulloa, García de la Huerta, Jacques Cazzote, Franz Grillparzer y otros se han ocupado en muy diferentes épocas y desde perspectivas a veces diametralmente opuestas del apasionado y polémico amor de esta pareja, que por la propia condición de sus miembros siempre ha despertado la imaginación de los autores. La bibliografía crítica sobre las distintas versiones y la propia trayectoria de la leyenda ofrece la suficiente garantía como para no considerar imprescindible una revisión ${ }^{1}$. Pero tras terminar el capítulo de nuestra monografía sobre García de la Huerta ${ }^{2}$ dedicado a las versiones ante-

1 Véase G. Cirot, «Alphonse le Noble et la Juive de Tolède», Bulletin Hispanique, XXIV (1922), pp. 289-306; E. Lambert, «Alphonse de Castille et la Juive de Tolède», Bulletin Hispanique, XXV (1923), pp. 371-94; E. Segura Covarsí, «La Raquel de García de la Huerta», Revista de Estudios Extremeños, VII (1951), pp. 197-234 y Lope de Vega, Las paces de los reyes y Judía de Toledo, ed. James A. Castañeda, Chapel Hill, The University of North Carolina Press, 1962.

2 Vicente García de la Huerta (1734-1787), Badajoz, Excma. Diputación Provincial 1987. 
riores a la suya, percibimos que las escritas en España durante el siglo XIX apenas merecían un ligero comentario, una condena por su supuesta falta de calidad y el consiguiente olvido. Otros estudiosos de la leyenda ni siquiera examinan estas versiones. No pretendemos negar las razones que para ello pudieran existir, pero si escribimos estas líneas es para al menos subsanar un olvido bibliográfico y examinar críticamente una nueva versión de la historia de la Judía de Toledo. Nos estamos refiriendo a una novela histórica, que como tantas obras de este género, no ha solido merecer el interés de la crítica ni siquiera para citarla: $\mathbf{R a}$ quel, de Joaquín Pardo de la Casta ${ }^{3}$.

E. Lambert, al hablar de este autor, se refiere al drama histórico que sobre el mismo sujeto, y casi con idéntico planteamiento, publicó en $1859^{4}$. Pero olvida que diez años antes el mismo escritor valencia-

3 Raquel, Valencia, Imp. J. Rius, 1849, 2 vols.; fue reeditada sin ninguna variante en Madrid, Tip. de A. Vicente, 1852. Fue publicada por primera vez en las páginas del semanario valenciano La Esmeralda, cuando el autor contaba 18 años. Este mismo publicó otra novela histórica titulada Zelim-Almanzor, Madrid, Imp. de A. Vicente, 1853, que tiene como marco la Valencia de la expulsión de los moriscos.

4 Raquel o los amores de Alfonso VIII, Rey de Castilla, Drama histórico en cinco actos y en prosa, Zaragoza, Imp. de V. Andrés 1859; la copia manuscrita presentada a censura se encuentra en B. N. M., Ms. 14.478-9. También hemos consultado una tercera edición publicada en La Coruña, Tip. Galaica, 1866, que no registra ninguna variante. Sin embargo, nos encontramos ante un problema bibliográfico. Mientras que la novela está firmada por Joaquín Pardo de la Casta, el drama es de Pedro Pardo de la Casta. ¿Dos hermanos o un solo autor? Manuel Ossorio y Bernard en su Ensayo de un catálogo de periodistas españoles del siglo XIX, Madrid, Imp. J. Palacios, 1903, p. 330, habla de dos autores, siendo Joaquín un político y senador valenciano que falleció el 13-II-1895 a los 71 años, mientras que de Pedro señala que se ve su firma en periódicos de La Coruña. Debemos añadir que este último figura como teniente coronel de Infantería en las ediciones de su drama. Juan I. Ferreras en su Catálogo de novelas y novelistas españoles, Madrid, Cátedra, 1979, p. 306, sólo hace referencia a Joaquín, aunque este dato únicamente nos sirve para saber que su hermano, de extstir, se dedicó al teatro y no la novela. Pero, en caso de que fueran dos autores hermanos, lo importante es que la obra es prácticamente la misma, salvo las lógicas adaptaciones de un género a otro. Sin embargo, hay frecuentes variantes entre el manuscrito del drama y sus ediciones, siendo la principal la que afecta al final. Mientras que en el primero la protagonista muere asesinada, en las ediciones se salva. ¿Recomendación de la censura, presiones de los actores, cambio de opinión del autor? Éste no parece tener una voluntad muy decidida de defender su texto, pues en la edición de 1866 añade esta soprendente nota: «Las compañías dramáticas que por falta de personal, vestuario, teatro a propósito $u$ otros motivos, no les fuere posible o conveniente representar por completo este drama, pueden poner sólo en escena los actos $1 .^{\circ}, 3 .^{\circ}$ y $5 .^{\circ}$, y suprimir la $1 .^{\mathrm{a}}$ y $2 .^{a}$ escena del $10^{\circ}$, combinando todo para este fin». ¿Si se puede suprimir la mitad de la obra...? 
no -o su hermano- había dado a la imprenta una novela titulada $\mathrm{Ra}$ quel, que fue reeditada en 1852, siendo ésta la edición que nosotros manejamos. Un simple cotejo entre el drama y la novela nos permite establecer que el primero no es sino el producto del ajuste a un nuevo género de lo ya planteado, con relativo acierto, en la obra narrativa. Salvo el significativo cambio en el desenlace, cuyas razones examinaremos posteriormente, todo permanece igual. Por lo tanto, podemos afirmar que la verdadera versión es la de Joaquín Pardo de la Casta y su novela histórica, siendo el drama una simple adaptación nada difícil, además, por las peculiaridades del propio relato. Pero esta pequeña precisión bibliográfica apenas tendría interés si la lectura de la obra que nos ocupa no presentara una versión muy distinta a las anteriores. Pardo de la Casta, en tanto que autor de un género tan caracterizado como es el de la novela histórica de la época romántica, fue un verdadero innovador con respecto a la leyenda. Y creemos que su versión merece ser analizada.

Resulta indudable que los distintos géneros literarios en que se inscriben las diferentes versiones de la leyenda determinan buena parte de los rasgos de las mismas. Pero esto se acentúa en el caso de la novela histórica de Pardo de la Casta hasta provocar una ruptura casi total con las recreaciones anteriores. Las razones pueden ser múltiples, aunque se centren en el férreo modelo impuesto por el citado género en la época romántica. En un trabajo actualmente en prensa ya explicaba como los autores del mismo son artesanos que no crean, sino construyen novelas históricas respondiendo a unas pautas fijas que dejaban escaso margen a la labor individual o a la peculiaridad de la temática abordada ${ }^{5}$. Si Pardo de la Casta quería abordar la leyenda, tenía que adaptarla no a una visión personal, sino a lo que establecía el género. Como consecuencia, hace caso omiso de las anteriores versiones, reduce la historia de la Judía de Toledo a la pura anécdota y todo lo demás, lo verdaderamente sustancial, pertenece al mundo de la novela histórica. Pardo de la Casta domina con acierto los resortes de la misma y con una narrativa elemental y correcta sabe encontrar los elementos necesarios para distraer a su lectorado - objetivo casi único de la mayoría de estos textoscon una historia que se parece a otras tantas de aquel prolijo género novelístico.

5 «La novela histórica en Alicante», La literatura en Alicante, 1839-1886, Universidad de Alicante 1987, pp. 36-72, en donde desarrollo un comentario de Ramón Sijé en La decadencia de la flauta y el reinado de los fantasmas. Ensayo sobre el romanticismo histórico en España, Alicante, Inst. Estudios Alicantinos, 1973, p. 194. 
Desde esta perspectiva vamos a intentar mostrar algunos rasgos de la Raquel de Pardo de la Casta. A diferencia de las anteriores versiones, aquí se nos indica el origen familiar y social de la protagonista. Como personaje novelístico habría sido poco aceptable presentar a la judía sin ese marco u origen, soslayado sin ninguna dificultad en los poemas y dramas de las demás recreaciones. No obstante, estas coordenadas de Raquel se limitan a las exigencias mínimas requeridas por la novela histórica. Estamos muy lejos todavía del realismo y el naturalismo y los autores sólo citan ese marco sin que el personaje tenga que responder al mismo. Nunca se establece una relación entre el sujeto y el medio ambiente porque la trayectoria de todos los protagonistas está predeterminada por las propias pautas del género.

No obstante, Pardo de la Casta nos explica que Raquel habita en el arrabal toledano, donde ocupa la mejor casa gracias a la riqueza derivada de las consabidas, y muy novelísticas, dotes de alquimista de su padre, el viejo Isaac. El autor es consciente de las tremendas diferencias que separan a la judía del rey, y no considera necesario forzar la situación mostrándola como pobre o huérfana, tal y como era habitual en el género. Tampoco la presentará como una concubina o algo que se le pudiera parecer. Raquel posee un alma tan pura, cándida y enamorada como la de cualquier heroína de la novela histórica. Su desgraciado destino, tan romántico, se basa en su condición de hebrea. Pero Pardo de la Casta, a diferencia de las anteriores versiones, obvia cualquier prejuicio antisemita. Este tendría en 1849 una vigencia muy inferior a la de los siglos XVII y XVIII, pero-la razón habría que buscarla en la necesidad de preservar la candorosa imagen de las heroínas de estas novelas. Así, aunque viviera en un arrabal pobre donde - como señala el propio autor - se padecía un constante temor ante las amenazas cristianas, ella es una flor intacta capaz de cautivar al ballestero Enrique, bajo cuyo disfraz se esconde Alfonso VIII.

Desde el principio de la novela, Pardo de la Casta concreta la coordenada cronológica y la geográfica. Una concreción que apenas había preocupado a los autores de las anteriores versiones, centradas casi exclusivamente en las relaciones entre la judía y el rey. Nuestro autor no tiene ninguna intención historicista y no se documenta sobre dichas coordenadas - lo cual era muy frecuente en la novela histórica-, pero para responder a las pautas del género las citadas relaciones tienen un marco ideal en el Toledo medieval. Pardo de la Casta se recrea por sus calles 
y ambientes en la medida en que se ajustan a la imagen tópica de la Edad Media mantenida por la novela histórica. Raquel no cae en la agobiante acumulación de lances y peripecias de la «novela de aventuras históricas» ${ }^{6}$, lo cual favorece una inusual brevedad del texto. Su acción novelesca es limitada, mientras que las descripciones y los elementos de ambientación son abundantes con el fin de crear una imagen de época. Esta no es otra que la marcada por la propia tradición del género, pero resulta suficiente para despertar la imaginación de un lector que disfrutaría con la presentación de justas, torneos, desfiles militares, circo, teatro..., que Pardo de la Casta incluye en su obra. A menudo, la leyenda de la judía y el rey acaba pasando a un segundo plano, pero no olvidemos que sólo era una excusa para que el autor escribiera una prototípica novela histórica.

La caracterización de los personajes también responde a las pautas del género. Su aspecto físico es consustancial a la maldad o bondad de sus acciones. La belleza arquetípica y casta de Raquel, la galanura de los nobles y la fealdad inquietante y siniestra de la vieja que asesinará a la protagonista sirven para que el lector no tenga ninguna duda sobre el comportamiento de los personajes. Dentro de esta ingenua caracterización el elemento psicológico queda reducido al mínimo. Y éste se centra en el deseo de venganza o en la ambición de los malvados y en la pasión amorosa de la pareja protagonista. Raquel provoca que Enrique -Alfonso VIII - consiga descubrir el sentido del amor. El rey queda «humanizado» y no se trata de ocultar su extremada sensibilidad, lo profundo e intenso de su sentimiento por la judía. Pardo de la Casta, a diferencia de las versiones anteriores, no condena que el monarca se enamore y deje de ser el guerrero de otras épocas, pues como personaje romántico - sin claudicar en su honor y valor- es en el amor donde puede encontrar el sentido de su vida. Sólo Luis de Ulloa había prestado tanta atención a este aspecto, pero nuestro autor le confiere el romántico carácter de personaje fatalmente enamorado e incapaz de superar racionalmente ese sentimiento. Ello es comprensible porque todavía estamos en la época romántica — sobre todo para un joven autor de 18 años que sólo conocería obras del citado movimiento-, pero tam-

6 Juan I. Ferreras la incluye en la categoría de la «novela histórica de aventuras», vẻase El triunfo del liberalismo y la novela histórica (1830-1870), Madrid, Taurus, 1976, p. 172. Guillermo Zellers no la incluye en su estudio La novela histórica en España (1828-1850), Nueva York, Inst. de las Españas, 1938. 
bién porque en este texto Pardo de la Casta reduce al rey a un personaje novelístico. Dentro de la variable relación Historia/ficción que se da como base de este género, en Raquel predomina de forma absoluta el segundo elemento. No hay ninguna preocupación historicista y Alfonso VIII puede presentarse como un enamorado de la literatura romántica.

El enamoramiento de Raquel es tan intenso como el de su pareja. Pero, a diferencia de las anteriores versiones, tras este amor no cabe la sospecha de segundas intenciones, de ambición personal o de defensa de la comunidad hebrea. No cabe la posibilidad de que la bella heroína de una novela histórica sea una taimada ambiciosa, ni siquiera que sea un personaje trágicamente contradictorio que se debata entre el amor y el interés. Pardo de la Casta está obligado a mostrar un personaje rectilíneo. Así, Raquel se enamora de un ballestero que, al presentarse como el rey, tendrá que seguir siendo Enrique, el ballestero, porque la candorosa protagonista no consiente que se mezcle el amor con la ambición. Ello impide que, a diferencia de las anteriores versiones, esta relación tenga implicaciones en la lucha por el poder. La nobleza no reacciona como estamento frente a la presencia de Raquel junto al monarca ${ }^{7}$, ni la hebrea intenta instrumentalizar su amor en favor de su comunidad. Es cierto que los judíos dejan de sufrir persecuciones durante un tiempo por orden del rey, pero sin que lo reclamara Raquel, la cual sólo es ingenuamente bella y enamorada.

Tal despreocupación por el elemento histórico, la reducción de los personajes y las situaciones a una ficción convencional propia de este género novelístico, favorecen la desaparición de cualquier implicación ideológica o política. Al contrario de lo que sucediera en la Raquel de García de la Huerta, Pardo de la Casta se centra en las intrigas, amores, celos, odios, traiciones, venganzas, juramentos, conspiraciones y asesinatos propios de una novela histórica de la época. De ellos no se puede deducir nada situado al margen de la misma ficción, al igual que ocurriera en la mayoría de las obras de este género, en el que el liberalismo o el conservadurismo de la «vuelta al pasado» suelen ser una quimera de los críticos.

7 Los únicos que sienten temor por la situación del reino a causa del enamoramiento del rey son los eclesiásticos (pp. 118-119), pero este peligro sólo es una posibilidad apuntada que no tiene importancia real dentro de la novela; constituye un aspecto secundario para el autor en la medida - entre otras cosas- en que también lo sería para sus lectores. 
Otro elemento fundamental de toda novela histórica que también encontramos en la Raquel es la ambientación, que se consigue con la combinación de una serie de elementos imprescindibles y constantemente repetidos en estas novelas. Las noches tormentosas, los palacios vacíos, el aullar de los perros, las expresiones cadavéricas, el golpear de puertas y ventanas, los torneos medievales, las bellezas melancólicas, los venenos, los laboratorios de alquimia repletos de libros viejos, pergaminos y reptiles disecados..., y un largo etcétera de elementos dispares pero que al lector le parecerían consustanciales con toda novela histórica. Una ambientación romántica, pero que ante todo es la predeterminada por este género o, lo que es igual, la que deseaban ver aquellos lectores. Pardo de la Casta, como tantos artesanos de esta novelística, con sus abundantes descripciones - que se complementan con las láminas- más que mostrar un ideal estético propio intenta satisfacer la imaginación de un lectorado que disfrutaría con la visión de arrogantes caballeros y damas delicadamente elegantes. El resultado es una cierta imagen de época, pero tan medieval como las clases medias del siglo XIX.

$\mathrm{Si}$, como he dicho anteriormente, todo lo acontecido en la novela se explica dentro de los cauces del propio género sin que se establezca ninguna relación con el mundo real, es comprensible la peculiar trayectoria del personaje del rey. Resulta llamativo que, tras haber estudiado las polémicas que suscitó el Alfonso VIII de García de la Huerta por contravenir el principio del decoro, nos encontremos con un monarca disfrazado de ballestero por el arrabal judío en búsqueda nocturna de su amada. Un rey que ignora olímpicamente a su esposa, que nunca muestra una preocupación por la razón de Estado y que vive su pasión amorosa con tanta intensidad como carencia de dudas y contradicciones. Y todo ello sin que Pardo de la Casta emita ningún comentario moralizador. Aquí el dieciochesco concepto del decoro ya se ha roto por completo, pero no a causa de una deliberada transgresión de las normas morales, ideológicas o de otro tipo. La única causa es la búsqueda del atractivo novelístico capaz de entretener al lector. No se trata de escribir la historia de un rey, sino de adecuarla a lo establecido para un héroe enamorado de la novelística popular de la época. El que en vez de Gautiero de Armengol, Gutierre Gelmírez, Diego de Luna... se llame Alfonso VIII da exactamente igual. Incluso se le puede permitir que se muestre dispuesto a abandonar la corte y la corona para huir con Raquel, «como dos peregrinos de amor, a buscar el lugar más ale- 
gre y más escondido de la tierra» (pág. 169). Al fin y al cabo, es un héroe enamorado que responde a lo marcado para este tipo.

Sin embargo, tal apasionamiento y el fatal desenlace de la historia podrían parecer demasiado atrevidos a algunos lectores. Si Pardo de la Casta se hubiera sentido identificado con esta relación amorosa entre el rey y la judía la habría llevado hasta sus últimas consecuencias, habría creado un nuevo drama de amor dentro de la literatura romántica. Pero a un artesano no se le puede pedir esta identificación y no nos debe extrañar que al final incluya un «Epílogo» donde se suaviza, y hasta anula, el elemento trágico y transgresor de esta apasionada historia amorosa ${ }^{8}$. Después del envenenamiento largo y dramáticamente prolongado de la heroína - que se inscribe en un final rocambolesco y sangriento-, Pardo de la Casta parece pensar que las cosas no podían quedar tan mal y en el «Epílogo» nos dice que Alfonso VIII olvidó a Raquel y fue un buen rey que compartió la felicidad con doña Leonor, la esposa que le perdonó lo que de un amor trágico pasa a convertirse en un desliz. Hay que emocionarse y padecer con el relato, pero éste es pura ficción y al final todo vuelve a la normalidad y el orden.

La novela de Pardo de la Casta tiene graves limitaciones, pero no más que las habituales en su género. A pesar de su juventud, el autor domina los resortes básicos y consigue mantener un cierto interés que evita el hastío provocado por la mayoria de las novelas históricas españolas. Pero ello no es suficiente para crear una obra mínimamente personal que añada algo a una leyenda tantas veces recreada. Pardo de la Casta se limita a incorporar el núcleo elemental de la historia -el amor entre la judía y el rey- a una narración cuyo discurrir es ajeno al propio autor. En su Raquel encontramos elementos, situaciones y personajes nuevos con respecto a las anteriores versiones, pero jamás son el fruto de la lectura de la leyenda realizada por Pardo de la Casta. Ésta no existe nunca, y la consecuencia es que su obra emprobrece y vulgariza la trágica relación amorosa de Raquel y Alfonso VIII. Pero, tras leer esta y otras novelas históricas, nos planteamos la siguiente pregunta: ¿fue capaz este género de enriquecer el pasado histórico abordado? Creo que, mayoritariamente, no. Si estuviéramos ante verdaderas novelas históricas la respuesta sería distinta, pero entre nosotros este novelar —si

8 Cfr. con los diferentes finales del manuscrito y las ediciones impresas del homónimo drama teatral. 
le aplicamos unos criteros de definición algo serios - fue minoritario. En manos de autores de segunda fila, sin el prestigio suficiente entre los sectores cultos, escritas mecánicamente sin una voluntad estilística y creadora y destinadas a satisfacer las monótonas necesidades de unos lectores poco exigentes, estas novelas no respondieron a las expectativas de un género que por definición abría muchas posibilidades. La $\mathrm{Ra}$ quel de Pardo de la Casta es una más y en sus páginas las sugerencias de la trágica historia de amor quedan reducidas a lo obvio de un relato para entretener a los lectores.

En el siglo XIX la leyenda de la Judía de Toledo tuvo varias versiones teatrales, todas ellas desafortunadas e incapaces de aportar algo nuevo a una historia que había dado sus mejores frutos en los textos de Luis de Ulloa y García de la Huerta. La primera de estas versiones es un anónimo «Diálogo trágico», que se inscribe dentro del género de los melólogos ${ }^{9}$. Estos alcanzaron su máxima difusión en España durante la última década del siglo XVIII, pero continuaron publicándose a principios del XIX para abastecer las representaciones en casas particulares, tan frecuentes en la época. El mismo editor de Raquel utiliza la consabida frase «Fácil de executar en casas particulares», que se solía poner como reclamo en todos estos textos. Por lo tanto, es en el peculiar marco de estas representaciones donde debemos entender las limitaciones - muy graves- de un género que tuvo más repercusión en las costumbres sociales y culturales de la época que en el ámbito verdaderamente teatral ${ }^{10}$.

El melólogo se caracteriza por la combinación del drama hablado y su comentario orquestal. La frase hablada queda preparada o realzada por la frase musical, la cual, en ciertos casos, igualmente interpretaría de un modo sonoro la mímica del actor. Se produce, pues, un nexo

9 Diálogo trágico / Titulado / La Raquel / Fácil de executar en casas / Particulares. / Sacado de la Historia, / Y adornado con intervalos de música. / Por un aficionado. Valencia, Imp. José Ferrer de Orga, 1813 (B. N. M., T/ 23772). Tuvo dos reediciones: Valencia, Imp. Ildefonso Mompié, 1817 (B. N. M., T/25532) y s.1., s.i., s. a. (B. N. M., T/649). José Subirá extracta las anotaciones del texto en El compositor Iriarte y el cultivo español del melólogo (melodrama), Barcelona, C. S. I. C., 1942, vol. II, pp. 363-4.

10 Sobre las condiciones que debían reunir las obras destinadas a las representaciones en casas particulares, véase mi ponencia «La obra de José Concha destinada a los teatros particulares» en el Coloquio Internacional sobre el teatro español del siglo XVIII, Bolonia, Octubre 1985 (en prensa). 
entre palabra, gesto y música. Las posibilidades del género son indudables, pero se centrarían en la expresión dramática, en el mismo acto de la representación, sin que tuvieran influencia en el tratamiento de las historias o temas elegidos para el melólogo. Así ocurre con el Guzmán el Bueno de Tomás de Iriarte, y también con la anónima Raquel. Es indudable que la utilización conjunta de la música, la mímica y la palabra suponía un paso adelante en un teatro no demasiado proclive a la innovación en la expresión dramática. De algunas obras se conservan las partituras musicales, pero lo que nosotros conocemos, los textos, tiene escaso interés.

Los melólogos, como muchas de las obras representadas en casas particulares, suelen adaptar lo escenificado en los teatros públicos a las peculiares circunstancias de estas representaciones. Ello supone a menudo un lógico empobrecimiento por la tendencia a reducir hasta lo esquemático el tema o la historia abordados por la obra. En el caso concreto del melólogo resulta especialmente grave por lo reducido del tiempo de representación, que obliga a una condensación excesiva del conflicto dramático expuesto. Éste es el principal defecto de la anónima $R a$ quel, que intenta resumir toda la trágica historia de la leyenda en una sola escena donde se da un largo monólogo de Raquel debatiéndose entre sus dudas y el amor y un breve diálogo — más bien dos monólogos paralelos - entre Alfonso VIII y ella. La escena termina con el asesinato de la judía y el arrepentimiento del rey tras su extravío. Lógicamente, el público admitiría la historia porque ya la conocería por su representación en los teatros públicos, pero si sólo tenemos en nuestras manos el anónimo texto resulta un tanto grotesco y absolutamente empobrecedor este intento de extractar la tragedia.

Los espectadores de aquellas representaciones no esperarían enriquecer su visión de la leyenda, sino ver en sus propias casas a algunos amigos escenificando lo que habían admirado en el teatro público. Para ello el anónimo autor les proporciona una buena serie de versos sonoros, la posibilidad de algunos aspavientos y les condensa la tragedia sin agotarles con ningún tipo de preámbulo. Les permite, como en tantas obras de estas características, la posibilidad de disfrazarse de Alfonso y Raquel sin tener que asumir o desarrollar los personajes. Esto nos indica que la leyenda - al menos la anécdota central- sería relativamente conocida en la época, pero también que no es en el melólogo donde se podría haber aportado algo nuevo. 
Lo mismo sucede con dos dramas líricos de finales del siglo XIX. De nuevo las limitaciones del género en que se inscriben las versiones anulan de partida la posibilidad de una verdadera recreación. Esto sucede especialmente en la lamentable y un tanto hilarante obra de Angel Lasso de la Vega ${ }^{11}$. En realidad, no se puede hablar de una versión, pues este brevísimo texto se limita a presentar escuetamente dos escenas de la leyenda. Las suficientes para el lucimiento de alguna actriz melodramática que se acompañara eficazmente con la música. Los versos son infames y apenas encontramos una mínima estructura dramática. Pero no creo que el autor y los espectadores estuvieran muy preocupados por ello, pues lo importante era la posiblidad de disfrutar de algún aspaviento melodramático tan propio de aquellos dramas líricos que permanecen en un justificado olvido.

Dentro del mismo género, el prolífico autor alicantino Mariano Capdepón escribió una nueva versión de la leyenda ${ }^{12}$. A pesar de que tiene una mínima consistencia dramática y está más elaborada que la de Lasso de la Vega, el resultado es mediocre. Desconocemos el valor de la parte musical, pero en lo que se refiere al texto resulta indudable que la leyenda queda empobrecida. Capdepón repite por enésima vez la anécdota central de la misma, pero es incapaz de darle un tratamiento personal e innovador. Sólo busca unos versos grotescamente tremendistas y, suponemos, anacrónicos, que aparentaran una tragedia inexistente en el juego de unos personajes reducidos a monigotes declamatorios. Al público le interesaría la música, los coros, mientras que los diálogos

11 Raquel. Drama lírico en un acto y en verso. Letra de... Música del maestro Don Joaquín Taboada Steger. Representado por vez primera con extraordinario éxito en el Teatro del Príncipe Alfonso el 30 de mayo de 1891, Madrid, Florencio Fiscowich Ed., 1891. Del mismo autor es El llanto de Raquel, Madrid, Imp. Ricardo Elers, 1849 , pero no guarda relación con la leyenda.

12 Raquel. Drama en tres actos original de---. Música del Maestro Antonio Santamaría. Representado por primera vez en el Teatro Real, traducido al italiano. Madrid, Imp. de José Rodríguez, $1891^{2}$. Otra versión teatral y decimonónica de la leyenda es la de Eusebio Asquerino, La Judía de Toledo. Drama histórico. Galería Dramática, t. XLI, Madrid, 1842, que ya fue estudiado por E. Lambert, «La Juive de Tolède de Grillparzer, étude sur la composition et les sources de la pièce», Revue de Litterature Comparée, abril-junio, 1922, pp. 238-79; vid. pp. 271-3, donde se extracta el argumento de este rocambolesco drama, que al representarse en 1843 en el Teatro de la Cruz dio origen a un curioso episodio recogido por Salvador García en Las ideas literarias en España entre 1840 y 1850 , University of California Press, 1971, p. 27. 
- los actores que estrenaron la obra eran italianos - serían un mero relleno. No obstante, Capdepón - que conoce la versión de García de la Huerta y la imita en lo más superficial- contribuiría al hipotético éxito de la obra con una tremenda escena final en la que Raquel se suicida para demostrar a Alfonso VIII su amor, y éste intenta seguirla conmovido ante semejante prueba. Tales situaciones, si no tienen un mínimo de calidad poética, producen hilaridad, y así sucede. Pero, ¿por qué seguirían siendo admitidas por el público de entonces? Seguramente, porque eran lo normal y repetido por enésima vez en un género, el drama lírico, que como tantos otros del siglo XIX cayó en manos de adocenados artesanos literarios sin ninguna aspiración que no fuera el seguir el camino ya trazado.

En definitiva, hemos comprobado que el verdadero interés literario de la leyenda acaba en el ámbito de la literatura española con la versión de García de la Huerta. A lo largo del siglo XIX no hay una correlación entre el número de veces que vuelve a aparecer y la calidad de los textos. La razón básica reside en que estas obras nunca responden a la voluntad creadora de un autor verdaderamente interesado por la leyenda. El único interés es el de escribir un melólogo, una novela histórica o un drama lírico que se ajustaran a las normas establecidas. Y para ello era adecuada la historia de Raquel y Alfonso VIII. Se podría decir que García de la Huerta también instrumentaliza la leyenda, aunque fuera con una finalidad ideológica y política. Es cierto, pero nunca olvida que ante todo escribe una tragedia en donde puede plasmar su concepción estética de la poesía y, lejos de reducir la historia a lo obvio, desarrolla sus sugerencias con una voluntad creadora sólo superada por la belleza barroca del poema de Luis de Ulloa. Los autores del siglo XIX no siguen el mismo camino y utilizan la leyenda como una excusa, por lo que su empobrecimiento resulta inevitable. Pero, ¿cuántos melólogos, novelas históricas o dramas líricos leemos hoy con interés? Supongo que muy pocos, ya que el olvido es la consecuencia lógica de esta literatura decimonónica demasiado sujeta a los «géneros», excesivamente dictada por el público y mayoritariamente en manos de la inmensa nómina de artesanos literarios de la época. 